\title{
Study of Chinese Teaching Based on Aesthetics
}

\author{
Wei Xu \\ Shangluo University, 726000 , China
}

Keywords: Chinese teaching, Aesthetics, Teahcing relationship, Quality-oriented education

\begin{abstract}
Chinese is the abbreviation of language and literature, and it is a generic term of listening, speaking, reading and writing. The aim of Chinese discipline is to teach students to read and become literate, and more important thing is to spread cultural thoughts and advanced principles, and also is the way of people to comunicate, transfer thoughts. So, the Chinese discipline could be called "the art philosophy of beauty". And what are the relations between Chinese principle and aesthetics essence, its fundamental relation and aesthetic consciousness? Now, this paper would make an analysis on Chinese teaching of aesthetics and investigate the relations between Chinese teaching and aesthetics.
\end{abstract}

\section{Introduction}

China is one of the four great ancient civilizations, and is the seminary of society economy and culture, and has profound cultural and historical connotations. The central plains people of China has created the way of 'keeping records by tying knots' over three thousand years, and record the history by this way. But this way is not convenience and is not easy to carry. So, Cang Jie invented the characters and people begin to record informations by characters, it is the beginning of literature and art. From 'the book of songs' to 'Lisao', from 'Lisao' to verses, ditties, odes and songs, and frama, fictions and vernacular, there are more and more art skills in characters and language. So, the literature itself is one pattern of art. And Chinese teaching could use some suitable way to indicate literature and art, and help students to understand Chinese literature and pay attention to those literature.

\section{The overview of language arts}

This paper would make an analysis on the chinese teaching on the basis of aesthetics. And at the first, we need to understand the connotation of language arts, and expound the relation between chinese teaching and aesthetics through language arts. Chinese teaching appeared in the acient time, and is developed into a typical discipline, and become an platform for communicating across cultures and teaching characters. Chinese teaching become more and more important in the modern time, we could investigate other contents of other areas only on the basis of basic chinese language ${ }^{[1]}$.

The contents of chinese teaching are learning characters, groups of words, making sentence, understanding paper, writing and other things. Every item has a high artistic quality, and chinese character is a kind of artistic embodiment and it is influential and the symbol of China ancient civilization. Each character could be divided into different parts, and also could make a sentence by these characters, this is the magic of characters. For example, '看' means to blind one's eye by his hands and look ahead in the distance. And another example, '门' means to put objects in the door, so we put a batten on the door. These chinese characters has its initial meaings when they have been created. Therefore, the artistic quality of chinese teaching is strong. On the basis of chinese language and literature, teachers needs to guide and teach students to understand and learn chinese characters with their intuition.

\section{The artistic quality of Chinese teaching}

\section{The overview of the artistic quality of chinese teaching}

In consideration of chinese's particularity, chinese teaching is different with other areas. The foundation is its artistic quality, and could not exist without artistic quality of literature ${ }^{[2]}$. And the 
teachers are also the carrier of artistic behavior, and teacher's artistic quality, teaching process's artistic quality, learning process's artistic quality, teaching language's artistic quality are the concentrated reflection of artistic quality of chinese teaching. Through these expression and innovation, we could promote chinese teaching, and strengthen student's enthusiasm and creativity, and help them to cultivate artistic skills.

\section{The embodiment of artistic quality of Chinese teaching}

The artistic quality of teaching methods

Teaching methods are the direct indication of teaching means. For this reason, the level of traching methods could influence teaching effects, teaching efficiency and learning efficiency. And also the artistic quality of chinese teaching contains artistic quality of teaching methods. And how to express the artistic quality is the problem to be considered. It will rely on the situational teaching approach, this method refers to introduce those teaching background, teaching career into classroom, a good way is to broadcast a song before the class. But students would question this things if this song is related to the lessons and what is the relations? These doubts would strengthen student's enthusiasm and creativity and urge them to learn and investigate texts. This way of story could express texts by the way of role-playing, and help students to have a stereoscopic feeling.

The artistic quality of teaching language

Chinese are extensive and profound, and we could express same meaning with different words, and different combinations have different meanings. Usage, organization and expression of language could make classroom more interesting. Teachers also could use language with different momentum, something like euphemism, soft or high, give different texts different meanings, and also use some humor language to relax the class.

\section{The application value of aesthetics in Chinese teaching}

\section{The aesthetics is the basic content of chinese teaching}

The obiective of chinese teaching is not only enhance student's ideological level, but also feel artistic quality and beauty, and also help students to increase level of aesthetic judgment and ideological cultivation.

For example, "who is the cutest person?" expresses those warrior's valiant spirit which need students to learn. And other texts, "The lotus pool by moonlight", "the three gorges", "The travel literature of Tianshan", "Climbing mount tai in the rain", "Visit the yellow mountain" all introduce natural scenery, and make students appreciate these sceneries, and be proud for their country ${ }^{[4]}$. And on the other side, "Suzhou garden", "The venice" introduce architectural beauty. And "Shabby Market around the sea", "The flower city" and "The earth" introduce beauty of life. As to those fables, such as "Pulling up seedlings to help them grow", "Wait for windfalls" introduce some philosophical beauty which help students to distinguish the true and false and develop correct values of life and world. All these texts are the important contents of chinese teaching, and could expose the nature and the beauty of life ${ }^{[5]}$.

\section{The aesthetics is important means of updating chinese teaching}

In chinese teaching, the most basic teaching procedure is to understand text stucture, and help students learn writing skills through text study. From the point of aesthetics, the main task is to find connotation and definition of beauty. Take "Tribute to White Poplar" for example, this is a representative text. There are several aspects about its elegant structure:

At first, usage of '礼' to praise these extraordinary white poplar, and tell the reasons of extraordinary. And there are many 'beauty'. It describes its marvellous background at first, and describes its extraordinary temperament both in inside and outside. These aspects of extraordinary all contain th aesthetics and make students feel beauty with different level. This is called "beautiful scenery","person beauty", "beautiful spirit", which links all these structural dimension. Also the combination of materials are layer-layer prgressive, then put up a theme named "extraordinary"[6]. 


\section{The aesthetics is the key of student's comceptual work}

It is often said that the used key is always bright, but inactive key is always dark. We put this implied meaning into chinese teaching, this refers to put beauty into classroom, and would bring infinite charm and enjoyment. As follows are specific methods.

Try to comprehend text's quality. When we learn "who is the cutest person?", teachers could use parallelism to describe those excellent characters of protagonists. Such as, "How noble will these protagonist's characters are! How tough will these protagonist's volitions are ! How extensive will these protagonist's ambitions are! ". Here, teachers use three"these protagonist" to express their excellent qualities. And through this parallelism, we reveal their beauty of different aspects, such as beautiful quality, beautiful volition and beautiful ambitions and so on. These kind of beauty are produced under the patriotism ${ }^{[7]}$. The author exposes the spirit and beauty both from inside and outside aspects. To deepen understanding, teachers could tell some stories which could not only attract student's attendence, but also provide reference for their writing. For example, on the bank of Han River, I met a young warrior. He is 24 and named XXX from XXX. His face is swarthy with a little bit red, and this warrioris tall and strong. He standed on the front of corn and looked very simple and lovely in the background of those corns. Through the description about the personalities of the character and colourful language, the beauty could be revealed. Only by some guidence, students could feel a sense of beauty. We make chinese teaching and aesthetics band together, and each of them expresses its own features ${ }^{[8]}$.

Induce students into the simulation scenarios. The aesthetics could produce a specific situation for chinese teaching, and many texts about landscape description could produce different situations through aesthetics. For example, "The travel literature of Tianshan", this text describes the sceneries of Tianshan. At first, it starts with a elegant layout, and it is a typical travel notes which applies 'movement of steps and shift of scenes' and 'travelling places' ${ }^{[9]}$ and describes those different sceneries and priceless treasures in accordance with spatial distribution. For example, "make an overlook on the whole Tianshan, it is beautiful with snow-covered, and those peaks just like dancing uyghur girls; and those mountain range just like a peacock in his pride". Secondly, a suitable cutting on material. This text is famous for its short and exquisite, is a typical prose. There are more than 10 sceneries involving Xuefeng, weeds, ranches, forests, streams, snowlotus and natural lake, and destribes those sceneries with legends which make it more mysterious. Then describes its beauty of harmony, that national environment has bred rich resources, and people wait to exploit. In conclusion, this text could take advantage of a scene to express its emotion and also reflect aesthetics's functions.

Inspire imagination. Students have more imagination than adults and endless. And 'beauty' is the key to open the imagination and inspire them to think and create. Take a section of "The lotus pool by moonlight" for example, "The moonlight is streaming down through the foliage, casting bushy shadows on the ground from high above, dark and check ered, like an army of ghosts; whereas the bengin figures of the drooping willows, here and there, look like paintings on the Iotus leaves." Students could associate that beautiful moonlight by this sectio, and the center is the "beauty' which bring students different sense of beauty. "drooping willows" and "paintings on the Iotus leave" are a kind of embodiment of beauty. We could expound those words and leave students more imagination.

\section{Conclusion}

In conclusion, Chinese teaching is full of artistic quality, and there are artistic quality both in different stages and contents. For this purpose, we could improve Chinese teaching by using more forms of artistic presentation. And aesthetics is essential for artistic expression. By applying the aesthetics in text understanding, students could improve their ability of aesthetic judgment and sensory. Thus it can be seen the aesthetics is closely associated with Chinese teaching, these two reflect a complementary causal relation. This paper has made an analysis on the relations between aesthetics and Chinese teaching, and hope to provide assistance to teaching. 


\section{References}

[1] Wei wang, The constructivism between subjects-teaching difficulty in aesthetics and its countermeasure, The journal of Chengdu University of Technology (Social Science edition), 2013,21(1):28-32.

[2] Huiying $\mathrm{Su}$, Construction of teaching situation about aesthetics-establishment of harmonious and active politics teaching, China education innovation herald,2010(24):206-207,209.

[3] Aixian Geng, Discussion on the aesthetic education-analysis on restrictive factors of application of multimedia technology in aesthetic education, China Science and Technology Review, 2011(23):84-85.

[4] Yimin Jia, Yinghua Wang, The overseas Chinese teaching and cultural transmission-the summary of the 5 th postgraduate forum of overseas chinese teaching, Teaching and research on Chinese teaching,2013(2):18-23.

[5] Ming Wan, Chunyan Geng, The guidence on Chinese teaching by new concept of student - the determination of student-oriented in educational reform, Continue Education Research,2014(11):133-134. 